\title{
Structural Differentiation and Ambidexterity: The Mediating Role of Integration Mechanisms
}

\author{
Justin J. P. Jansen, Michiel P. Tempelaar, Frans A. J. van den Bosch, Henk W. Volberda \\ Rotterdam School of Management, Erasmus University, 3062 PA Rotterdam, The Netherlands \\ \{jjansen@rsm.nl, mtempelaar@rsm.nl, fbosch@rsm.nl, hvolberda@ rsm.nl\}
}

\begin{abstract}
Drior studies have emphasized that structural attributes are crucial to simultaneously pursuing exploration and exploitation, yet our understanding of antecedents of ambidexterity is still limited. Structural differentiation can help ambidextrous organizations to maintain multiple inconsistent and conflicting demands; however, differentiated exploratory and exploitative activities need to be mobilized, coordinated, integrated, and applied. Based on this idea, we delineate formal and informal senior team integration mechanisms (e.g., contingency rewards and social integration) and formal and informal organizational integration mechanisms (e.g., cross-functional interfaces and connectedness) and examine how they mediate the relationship between structural differentiation and ambidexterity. Overall, our findings suggest that the previously asserted direct effect of structural differentiation on ambidexterity operates through informal senior team (i.e., senior team social integration) and formal organizational (i.e., cross-functional interfaces) integration mechanisms. Through this richer explanation and empirical assessment, we contribute to a greater clarity and better understanding of how organizations may effectively pursue exploration and exploitation simultaneously to achieve ambidexterity.
\end{abstract}

Key words: ambidexterity; dynamic capabilities; structural differentiation; formal integration mechanisms; informal integration mechanisms; exploration; exploitation

History: Published online in Articles in Advance January 22, 2009.

Firms are increasingly confronted with paradoxical challenges of exploiting existing competencies and exploring new ones (Vera and Crossan 2004). Not only do firms need to generate new knowledge associated with new products and services for emerging markets, they also need to leverage current competences and exploit existing products and services (Danneels 2002). Achieving long-term success requires a dynamic capability enabling firms to satisfy current demands while simultaneously being prepared for tomorrow's developments (Gibson and Birkinshaw 2004). In this sense, prior literatures have argued that successful organizations are ambidextrous (Duncan 1976) - they generate competitive advantages through revolutionary and evolutionary change (Tushman and O'Reilly 1996), or exploratory and exploitative innovation (Benner and Tushman 2003, Jansen et al. 2006).

Whereas most studies have focused on competitive benefits (Gibson and Birkinshaw 2004, He and Wong 2004), far less attention has been given to uncovering how firms may achieve ambidexterity. Exploration and exploitation require fundamentally different and inconsistent architectures and competencies that create paradoxical challenges. Whereas exploration has been associated with flexibility, decentralization, and loose cultures, exploitation has been related to efficiency, centralization, and tight cultures (Benner and Tushman 2003). Recently, studies are beginning to address organizational attributes such as structural differentiation
(Gilbert 2005, Tushman and O'Reilly 1996) and organizational context (Gibson and Birkinshaw 2004) that enable firms to balance these conflicting demands and to achieve ambidexterity. However, there is little evidence about the role of structural differentiation and integration in ambidextrous organizations. Yet, scholars have emphasized that both attributes are core elements in the ability of firms to pursue exploratory and exploitative activities simultaneously (Siggelkow and Levinthal 2003, Tushman and O'Reilly 1996). We conceptualize organizational ambidexterity as an organizational-level dynamic capability and argue that structural differentiation and integration play a crucial role in a firm's ability to pursue exploratory and exploitative innovation concurrently.

This study adds to the emerging dialogue on organizational attributes of ambidexterity in at least three important ways. First, we recognize organizational ambidexterity as a dynamic capability by arguing that it refers to the routines and processes by which ambidextrous organizations mobilize, coordinate, and integrate dispersed contradictory efforts, and allocate, reallocate, combine, and recombine resources and assets across differentiated exploratory and exploitative units (O'Reilly and Tushman 2007, Teece 2007). We argue that organizations need to develop such a dynamic capability to implement effective ways of achieving ambidexterity. Our study broadens the conceptual interpretation of organizational ambidexterity and suggests that it is difficult to achieve yet rare and not easily imitated, and 
provides organizations with competitive advantages over time (Barney 1991). In this way, we contribute to recent research linking the dynamic capabilities framework to organizational ambidexterity (O'Reilly and Tushman 2007, Venkatraman et al. 2006).

Second, we provide new insights into the interrelationship between structural differentiation, integration, and ambidexterity. Structural differentiation, or the subdivision of organizational tasks into different units (Hall 1977, Lawrence and Lorsch 1967), can help ambidextrous organizations to maintain multiple competencies that address paradoxical demands (Gilbert 2005). It protects ongoing operations in exploitative units from interfering with emerging competences being developed in exploratory units. Hence, it ensures that exploratory units are able to enjoy the required freedom and flexibility to develop new knowledge and skills. Although structurally differentiating exploratory and exploitative activities is important to reduce resource and routine rigidity (Gilbert 2005), ambidextrous organizations also need to facilitate collective action (O'Reilly and Tushman 2004). Integrative efforts are therefore a necessary step into appropriating the potential value embedded in spatially separated activities (Sirmon et al. 2007). We argue that achieving ambidexterity requires the subsequent integration and application of differentiated exploratory and exploitative efforts without corrupting the internal structures and processes within each unit's area of operation (Gilbert 2006, O'Reilly and Tushman 2007). Accordingly, our study examines how integration mechanisms mediate the relationship between structural differentiation and achieving ambidexterity.

Third, scholars have acknowledged the importance of different types of integration mechanisms for becoming ambidextrous. For instance, previous research has suggested that ambidextrous designs involve differentiated organizational units and tight senior team integration (Benner and Tushman 2003, Tushman and O'Reilly 1996). Senior team integration contributes to balanced resource allocation and establishes cross-fertilization across exploratory and exploitative activities (Jansen et al. 2008, Smith and Tushman 2005). Other studies, however, have argued that ambidextrous organizations need to use formal and informal integration mechanisms to increase knowledge flows across differentiated exploratory and exploitative units (Gilbert 2006, Westerman et al. 2006). Such organizational integration mechanisms create permeability and enable organizations to obtain and apply strategically valuable combinations. Until now, the relative influence of senior team integration and organizational integration mechanisms is still unclear, and scholars have called for more research in this area. Our study distinguishes between senior team and organizational integration mechanisms, and investigates how these specific types mediate the relationship between structural differentiation and ambidexterity.
Figure 1 Hypothesized Model

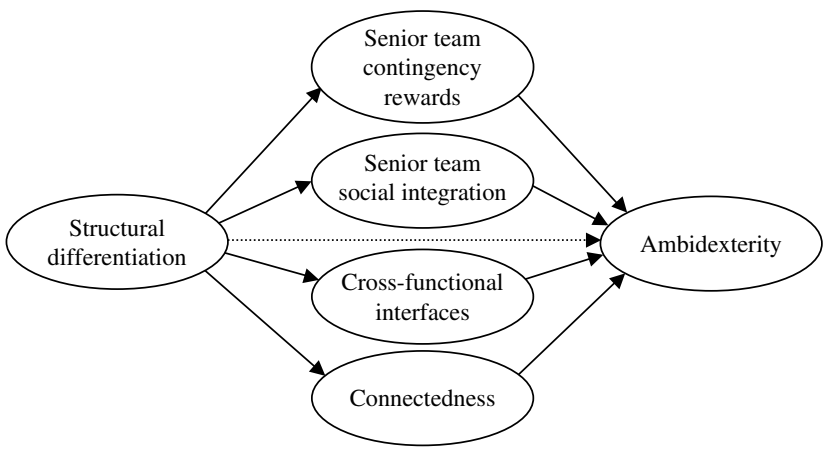

In the next section, we present the literature review and hypotheses underlying our research model as presented in Figure 1. Then, we present the empirical findings using data from 230 organizations operating in various industries. We conclude with a discussion of the results, implications, and issues for further research.

\section{Literature Review and Hypotheses}

\section{Exploration and Exploitation in Ambidextrous Organizations}

Studies have predominantly suggested that organizations pursuing exploration and exploitation simultaneously obtain superior financial performance (Gibson and Birkinshaw 2004, He and Wong 2004, Lubatkin et al. 2006). Combining exploration and exploitation not only helps organizations to overcome structural inertia that results from focusing on exploitation, but also refrains them from accelerating exploration without gaining benefits (Levinthal and March 1993). Although both types of activities are important for organizational survival, they create paradoxical challenges. Whereas exploration results from experimentation, flexibility, and divergent thinking, exploitation is associated with efficiency, refinement, and focus (March 1991). In this study, we apply the distinction between exploration and exploitation to learning and innovation, albeit of different types. Prior studies such as Benner and Tushman (2003), Danneels (2002), and He and Wong (2004) have explicitly embraced the idea that exploratory innovations are designed to meet the needs of emerging customers or markets. Exploratory innovations require new knowledge or departure from existing knowledge and the pursuit of new technological and customer competences (Danneels 2002, Jansen et al. 2006). They offer new designs, demand new systems and procedures, and attract new sets of customers through new channels of distribution (Abernathy and Clark 1985). Conversely, exploitative innovations meet the needs of existing customers or markets (Benner and Tushman 2003, He and Wong 2004). They deepen existing knowledge by 
refining established technological and customer competences (Danneels 2002, Jansen et al. 2006). Exploitative innovations improve established designs by applying existing skills and strengthening customer ties through an increase in the effectiveness of existing distribution channels (Abernathy and Clark 1985).

Based on an examination of prior literatures, Gupta et al. (2006) suggested two primary contenders of realizing a balance between exploratory and exploitative innovations: punctuated equilibrium and ambidexterity. Punctuated equilibrium refers a sequential pattern of longer periods of exploitation and short bursts of exploration (e.g., Burgelman 2002). Studies on the second contender, ambidexterity, consider exploration and exploitation to be orthogonal and refer to the simultaneous pursuit and combination of exploratory and exploitative innovation within organizations (e.g., Benner and Tushman 2003, Gibson and Birkinshaw 2004, Tushman and O'Reilly 1996). Ambidextrous organizations buffer exploratory efforts from exploitative activities by physically separating them across multiple yet loosely organizational units (O'Reilly and Tushman 2004). We contribute to this view on achieving ambidexterity by examining the idea that exploratory and exploitive activities should be differentiated yet subsequently integrated to generate value. We consider organizational ambidexterity as a dynamic capability that goes beyond moving from one competence configuration to another, but rather addresses and maintains multiple, inconsistent demands simultaneously (e.g., Gilbert 2006). Our approach allows us to uncover how ambidextrous organizations are able to successfully pursue multiple inconsistent innovation streams through generating integrative value across exploratory and exploitative units (Tushman et al. 2006).

\section{Structural Differentiation in Ambidextrous Organizations}

Prior studies have suggested that ambidextrous organizations are composed of structurally differentiated exploratory and exploitative units (Benner and Tushman 2003, Tushman and O'Reilly 1996). Structural differentiation refers to "the state of segmentation of the organizational system into subsystems, each of which tends to develop particular attributes in relation to the requirements posed by its relevant external environment" (Lawrence and Lorsch 1967, pp. 3-4). It establishes differences across organizational units in terms of mindsets, time orientations, functions, and product/market domains (Lawrence and Lorsch 1967, Golden and Ma 2003). In ambidextrous organizations, structural differentiation results in spatially dispersed exploratory and exploitative units at different locations (Benner and Tushman 2003, Tushman and O'Reilly 1996). It creates "pragmatic boundaries" (Carlile 2004) that safeguard experimental activities from dominant managerial cognitions and inertia present in the parent's mainstream activities (Benner and Tushman 2003). In this way, ambidextrous organizations allow the coexistence of inconsistent and paradoxical exploratory and exploitative efforts at different locations where motivation can be build entirely around emerging or mainstream business opportunities (Gilbert 2005). It provides a sense of freedom and ownership over specific work activities and generates structural flexibility to adapt to local conflicting task environments (Child 1984, Orton and Weick 1990).

\section{Realizing Integrative Value Across Differentiated Exploratory and Exploitative Units: Organizational Ambidexterity as a Dynamic Capability}

The coordination and integration of exploratory and exploitative efforts across organizational units is a necessary step in achieving ambidexterity (Gilbert 2006, Smith and Tushman 2005, Tushman and O'Reilly 1996). As O'Reilly and Tushman (2007, p. 17) suggest "the crucial task here is not the simple organizational structural decision in which the exploratory and exploitative subunits are separated, but the processes by which these units are integrated in a value enhancing way." The pursuit of exploratory and exploitative activities in differentiated units may lead to distinct operational capabilities or competences at dispersed locations (Gilbert 2006). It enables organizations to effectively execute routine day-to-day activities and produce desired output (Winter 2003). However, for these differentiated competences to be useful, they must be effectively allocated, mobilized, and integrated to generate new combinations of exploratory and exploitative innovation (Sirmon et al. 2007). The implementation or deployment of such combinations and the achievement of ambidexterity requires new organizing logics and collective patterns of interaction (Helfat and Peteraf 2003). The dynamic capabilities framework recognizes this important aspect. It argues that dynamic capabilities, which are embedded in the distinct ways that organizations integrate, build, and recombine competences flexibly across boundaries, are fundamental to long-term strategic advantage (Eisenhardt and Martin 2000, Henderson and Cockburn 1994, Kogut and Zander 1992, Teece et al. 1997). Accordingly, we link research on ambidexterity to the dynamic capabilities framework. We propose that organizational ambidexterity refers to the routines and processes by which organizations mobilize, coordinate, and integrate dispersed exploratory and exploitative efforts, and allocate, reallocate, combine, and recombine resources and assets across differentiated units. Organizational ambidexterity is a dynamic capability that creates valuable new configurations of exploratory and exploitative innovation by generating and connecting previously unconnected ideas and knowledge or recombining previously connected knowledge in 
new ways (Kogut and Zander 1992). For example, Iansiti and Clark (1994) argued that it is not the generation of detailed knowledge sources within different domains (i.e., operational capabilities at exploratory and exploitative units) that is crucial, but rather the usage of architectural knowledge to generate new possibilities for meeting multiple contradictory customer demands. Thus, the mere copresence of exploratory and exploitative activities in structurally differentiated organizational units does not ensure the simultaneous pursuit of exploratory and exploitative innovation. Achieving ambidexterity creates paradoxical situations because the short-term efficiency and control focus of exploitative units is at odds with the long-term experimental focus and decentralized architectures of exploratory units (Floyd and Lane 2000). When differentiating exploratory and exploitative efforts, organizations need to subsequently establish certain integration mechanisms to coordinate and integrate operational capabilities developed at spatially dispersed locations. Hence, to resolve these paradoxical situations, the mobilization, integration, and deployment of operational capabilities at exploratory and exploitative units are a necessary step in appropriating value and achieving ambidexterity.

Organizational ambidexterity as a dynamic capability is Path dependent in its emergence and idiosyncratic in detail; however, it exhibits common features (Eisenhardt and Martin 2000, p. 1116; Jansen et al. 2005). We indicate that these commonalties involve distinct integration mechanisms, such as senior team social integration and cross-functional interfaces, each of which provides specific ways of dealing with structural differentiation in ambidextrous organizations (O'Reilly and Tushman 2004). We suggest four types of integration mechanisms along two dimensions: (1) senior team versus organizational and (2) formal versus informal integration mechanisms as common features of organizational ambidexterity. First, prior studies have pointed at the distinct roles of senior team and organizational integration mechanisms in achieving ambidexterity. Senior team integration mechanisms need to allow for the allocation of scarce resources and the departure from existing competences and skills within exploratory units (Gilbert 2005, Hill and Rothaermel 2003), yet establish cross-fertilization and strategic synergies with ongoing businesses in exploitative units (Jansen et al. 2008, Tushman and O'Reilly 1996). Additionally, organizational integration mechanisms need to enable ambidextrous organizations to access and integrate knowledge sources flexibly across relatively autonomous exploratory and exploitative units (Galunic and Eisenhardt 2001, Gilbert 2006, Henderson and Cockburn 1994). Second, based on the assumption that certain integration mechanisms are richer and provide a higher information-processing capacity, prior literatures have distinguished between formal and informal integration mechanisms (March and Simon 1958,
Tsai 2002, Van de Ven et al. 1976). Formal integration mechanisms are a means to coordinate and integrate differentiated activities through pre-established mechanisms and interfaces (Ghoshal et al. 1994). Informal integration mechanisms, on the other hand, refer to emergent social properties and have been found to be of influence on boundary spanning across different units (Galbraith 1973, Tsai 2002). To uncover how organizations reconcile conflicting demands across exploratory and exploitative units and achieve ambidexterity, we examine how formal as well as informal senior team and organizational integration mechanisms mediate the relationship between structural differentiation and ambidexterity (Martinez and Jarillo 1989, Westerman et al. 2006).

\section{The Mediating Role of Senior Team Integration Mechanisms}

Senior teams in ambidextrous organizations typically face role conflicts that may diminish acceptance of decisions (Jansen et al. 2008, O'Reilly and Tushman 2004). Especially when senior team members are responsible for differentiated exploratory and exploitative units, the likelihood of conflict is further exacerbated (Eisenhardt et al. 1997, Tushman and O'Reilly 1996). Structural differentiation may enhance self-interested behavior in which senior team members perceive direct competition regarding the allocation of scarce resources (Bower 1970). Senior teams in ambidextrous organizations are therefore expected to recognize and translate different, ambiguous, and conflicting expectations across differentiated exploratory and exploitative units into workable strategies. Resolving this tension in senior management teams is a crucial element in their organization's ability to create integrative and synergetic value across exploratory and exploitative activities and to achieve ambidexterity (Teece 2007). Hence, we examine the mediating role of two senior team integration mechanisms that are considered to be beneficial to combining strategic contradictions: formal senior team contingency rewards and informal senior team social integration (Jansen et al. 2008, Lubatkin et al. 2006, O'Reilly and Tushman 2004, Siegel and Hambrick 2005, Smith and Tushman 2005).

Senior Team Contingency Rewards. Contingency rewards, which reflect the degree to which benefits for individual team members depend on their team's outcome, are favorable to senior teams confronted with pressures for mutual adjustment (Harrison et al. 2002, Shaw et al. 2002, Wageman and Baker 1997). They create an outcome interdependency within senior management teams (Slavin 1996, Wageman 1995) and urge members to direct attention and behavior toward interdependent rather than individual activities (Siegel and Hambrick 2005). In this sense, ambidextrous organizations generate commitment to complex organizational 
goals (Bloom 1999, Harris and Bromiley 2007) and foster collaboration across senior team members responsible for differentiated exploratory and exploitative units. Additionally, team contingency rewards encourage senior team members to mobilize and integrate operational capabilities across differentiated units through identifying ways to encourage new combinations (Smith and Tushman 2005). In this sense, senior team members transcend their unit's direct interests and establish new ways to achieve ambidexterity. Moreover, ambidextrous organizations may establish contingency rewards to motivate senior team members to advance thinking and participate in clarifying problems and proposing solutions to complex issues (Wageman 1995). This reduces interpersonal competition and facilitates negotiation and mutual adjustment across differentiated units (Pfeffer 1995). Overall, ambidextrous organizations may use contingency rewards to reconcile conflicts associated with allocating resources to differentiated exploratory and exploitative efforts. Hence,

HYPOTHESIS 1. Senior team contingency rewards mediate the relationship between structural differentiation and ambidexterity.

Senior Team Social Integration. Social integration is a multifaceted phenomenon that reflects the "attraction to the group, satisfaction with other members of the group, and social interaction among the group members" (O'Reilly et al. 1989, p. 22). Socially integrated senior teams are associated with increased negotiation, compromise, and collaboration (Barkema and Shvyrkov 2007, Michel and Hambrick 1992). Members of socially integrated senior teams are not only expected to work harder to recognize and seize opportunities, but also to leverage operational capabilities across differentiated exploratory and exploitative units. Social integration increases collaborative problem solving (De Cremer et al. 2008) and facilitates senior executives to build realistic understandings of key preferences and conflicting roles in senior teams (Eisenhardt et al. 1997). In this sense, it provides comfortable and familiar platforms that routinize consideration of conflicting strategic agendas (Jehn et al. 1997). Hence, it stimulates critical debate that allows senior team members to evaluate and redesign potential combinations of knowledge sources at differentiated units. In this sense, senior team social integration contributes to the mobilization and integration of operational capabilities at differentiated units to arrive at new combinations of exploratory and exploitative activities. It mediates the relationship between structural differentiation and ambidexterity as social integration triggers alternative ways to reconciling conflicting goals across spatially distributes units and to generating portfolios of knowledge resources underlying new products and services.
HyPothesis 2. Senior team social integration mediates the relationship between structural differentiation and ambidexterity.

\section{The Mediating Role of Organizational Integration Mechanisms}

Where senior team integration mechanisms enable balanced resource allocation and strategic coherence in ambidextrous organizations, organizational integration mechanisms facilitate knowledge exchange and combination between differentiated exploratory and exploitative units (Kogut and Zander 1992, Tsai and Ghoshal 1998). Through combination and integration of differentiated skills and experiences, ambidextrous organizations are able to add or remove product subsystems or change linkages between subsystems underlying exploratory and exploitative innovations. Thus, they are able to synchronize, maintain, and further build portfolios of exploratory and exploitative innovation simultaneously (Tushman et al. 2006). Organizational integration mechanisms not only facilitate new value creation through linking previously unconnected knowledge sources (Cohen and Levinthal 1990), but also through providing opportunities to leverage common resources and obtaining synergies across exploratory and exploitative units (O'Reilly and Tushman 2007). Integrative efforts are vital to ambidextrous organizations as existing knowledge sources in exploitative units may need to be revisited, reinterpreted, and applied in exploratory units due to changes in the organization's strategy or environment (Garud and Nayyar 1994, Postrel 2002). We consider two organizational integration mechanisms that have been associated with knowledge combination and integration: formal cross-functional interfaces (Lawrence and Lorsch 1967, Martinez and Jarillo 1991) and informal social relations or connectedness (Jansen et al. 2006, Tsai and Ghoshal 1998).

Cross-Functional Interfaces. Ambidextrous organizations may use cross-functional interfaces such as liaison personnel, task forces, and teams (Gupta and Govindarajan 2000) to enable knowledge exchange across exploratory and exploitative units. Cross-functional teams and task forces bring together employees from differentiated units who have distinct expertise underlying innovation streams. They cut across exploratory and exploitative unit boundaries that are established by spatially separating fundamentally different learning modes. Knowledge sources underlying current products and services in units may be underexplored due to a lack of capabilities or complementary knowledge in exploratory units (Prabhu et al. 2005). Cross-functional interfaces facilitate organizational members from distinct units to reach a common frame of reference and to build understanding and agreement (Daft and Lengel 1986, Egelhoff 1991). Gilbert (2006), for instance, showed 
how a newspaper organization used cross-functional teams and task forces to overcome differences, interpret issues, and build understanding about paradoxical cognitive frames across their newspaper (i.e., exploitative) and internet publishing (i.e., exploratory) business units. Organizational members from both types of units are assembled in task forces or cross-functional teams. They represent a flexible formal arrangement because they can be disbanded after their specific task has been completed. In addition, liaison personnel are responsible for resolving differences across exploratory and exploitative units to overcome disagreement and to reduce equivocality of organizational goals (Daft and Lengel 1986). Cross-functional interfaces provide platforms that keep multiple innovation streams connected by disseminating operational capabilities and learning about new ways of achieving ambidexterity. Thus, crossfunctional interfaces facilitate the generation and recombination of knowledge sources, yet retain the integrity of contradictory structures and processes in exploratory and exploitative units (Dougherty 2001, Gilbert 2006).

Hypothesis 3. Cross-functional interfaces mediate the relationship between structural differentiation and ambidexterity.

Connectedness. Connectedness concerns the overall pattern of a firm's social network in terms of density (Nahapiet and Ghoshal 1998, Sheremata 2000) and facilitates knowledge exchange (Jaworski and Kohli 1993). Connectedness is essential for the emergence of shared codes and language. It provides a common base of understanding through which organizational members with disparate experience, knowledge, and backgrounds can transfer and integrate new ideas (Hansen 2002). Dense social relations within ambidextrous organizations combat the polarization across exploratory and exploitative units. They reduce the likelihood of conflict regarding goals and implementation by maintaining the permeability of unit boundaries (Nelson 1989, Rindfleisch and Moorman 2001). Increased interaction fosters collaborative conflict resolution because members from differentiated exploratory and exploitative units have greater opportunities for creating win-win situations. Krackhardt and Stern (1988) made a strong case for the efficacy of cross-cutting social ties as a conflict-reduction mechanism, arguing that the existence of dense social relations between organizational units reduce disruptive conflict. Nelson's (1989) study of intergroup ties indicates that frequent interactions between groups permit faster dispute resolution and prevent the accumulation of grievances and grudges. Informal social relations also serve as information bridges across exploratory and exploitative units, and contribute to the search for new applications of exploitative efforts or help those organizational members who want to advertise their exploitative efforts in new areas (Nahapiet and Ghoshal 1998). Thus, connectedness affects their ability and motivation to integrate and recombine differentiated knowledge sources at exploratory and exploitative units, thereby mediating the relationship between differentiation and ambidexterity.

HyPOTHESIS 4. Connectedness mediates the relationship between structural differentiation and ambidexterity.

\section{Methods}

\section{Research Setting and Data Collection}

We randomly identified a company sample (4,000 firms) using a database from a commercial provider. The sample covered a broad range of industries and was restricted to private firms with at least 25 employees. We ensured that the informants were professionally interested, conscientious, and committed to providing accurate data by assuring them of confidentiality and by offering them a summary of the results. To deal with potential problems associated with single-informant bias and common method bias, we temporarily separated the measurement of our independent and dependent variables and collected data at two different points in time. In 2005, a survey assessing structural differentiation, senior team integration mechanisms, and organizational integration mechanisms was administered to the executive director of our random sample of 4,000 companies. Executive directors of 452 companies returned their questionnaire, representing a response rate of $11.3 \%$. In 2006, approximately one year after the first survey, a second survey was mailed to the same 452 executive directors to assess their firm's exploratory and exploitative innovation. We received 230 usable surveys from executive directors, or $50.9 \%$ of the original response. The executive directors had a mean age of 47.56 years (standard deviation $($ s.d. $)=8.58)$ and amean company tenure of 13.64 years (s.d. $=10.18)$. Firms in the final sample had an average size of 519.74 (s.d. $=3,183.12$ ) full-time employees and an average age of 41.74 (s.d. = 35.52). The firms were operating in a wide range of industries covering manufacturing $(51.3 \%)$, construction $(16.5 \%)$, wholesale $(6.5 \%)$, transportation (5.2\%), financial services $(7.8 \%)$, other professional services $(12.2 \%)$, and other industries $(0.4 \%)$. To test for nonresponse bias, we examined differences between respondents and nonrespondents for our final sample. $T$-tests showed no significant differences based on the number of full-time employees, total assets of branches, and prior performance. We also compared early and late respondents in terms of demographics and model variables. These comparisons did not reveal any differences $(p<0.05)$, showing that nonresponse bias was not a problem.

To offset individual respondent bias and to examine reliability issues associated with single-informant data, we surveyed additional management team members in 
2005 and 2006. In 2005, this follow-up survey resulted in 38 responses, or $16.5 \%$ of the firms from the 2006 sample, that were comparable in size, age, and prior performance to our final sample. In 2006, we conducted the same follow-up for a result of 58 responses, or $25.7 \%$ of the 2006 sample. We calculated an interrater agreement score $\left(r_{w g}\right)$ for data on study variables using the 2005 response for the independent and mediator variables and the 2006 response for the dependent variable. The average $r_{w g}$ per variable (James et al. 1984) for structural differentiation (0.89), senior team contingency rewards $(0.87)$, senior team social integration (0.93), cross-functional integration (0.91), connectedness (0.95), exploratory innovation (0.94), and exploitative innovation (0.94) suggests adequate agreement amongst respondents.

\section{Measurement and Validation of Constructs}

Although our study mostly used multi-item scales that were verified through various analyses, an appropriate scale for structural differentiation was not available (items of constructs are provided in the appendix). Based on a review of relevant of literatures, we generated items to tap the domain of structural differentiation.

Dependent Variable: Ambidexterity. Following prior studies, we considered exploratory and exploitative innovation as orthogonal (Gibson and Birkinshaw 2004, Gupta et al. 2006, He and Wong 2004) and used a twostep approach to measure ambidexterity.

First, executive directors provided information on the level of exploratory and exploitative innovation. The measure for exploratory innovation was adapted from Jansen et al. (2006). The resulting four-item scale for exploratory innovation $(\alpha=0.86)$ captures the extent to which organizations depart from existing knowledge and pursue radical innovations for emerging customers or markets. A four-item scale $(\alpha=0.70)$ measures firmlevel exploitative innovation (Jansen et al. 2006) and captures the extent to which organizations build on existing knowledge and pursue incremental innovations that meet the needs of existing customers (Abernathy and Clark 1985, Benner and Tushman 2003, Smith and Tushman 2005). To provide evidence of convergent and discriminant validity for exploratory and exploitative innovation, we performed various analyses. Exploratory factor analysis clearly replicated the intended two-factor structure, with each item loading clearly on its intended factor (all factor loadings were above 0.71 with crossloadings below 0.21) and all factors having eigenvalues greater than one. In addition, we compared the scores on exploratory and exploitative innovation with a separate overall five-item scale of innovativeness (Zahra 1996; $\alpha=0.91)$. Our expectation that both types of innovation would be related to the overall measure of innovativeness was corroborated by significant positive correlations $(r=0.60, p<0.01 ; r=0.28, p<0.01)$. Finally, we validated the scales of both types of innovation with separate measures through which we asked respondents to indicate the percentage of revenues in the last three years that is attributable to (1) products and services that are totally new to the firm and (2) products and services that have been improved extensively. Correlations between the scores for exploratory and exploitative innovation, and both percentages, were much stronger $(r=0.17--0.36 ; p<0.01)$ than cross-correlations $(-0.03--0.04 ; p>0.10)$ between domains, providing evidence of the convergent and discriminant validity of both measures.

Second, prior studies have constructed measures for ambidexterity in distinct ways: subtracting (He and Wong 2004), multiplying (Gibson and Birkinshaw 2004), and adding (Lubatkin et al. 2006) exploratory and exploitative innovation. To develop a measure for ambidexterity, we followed the procedures recommended by Edwards (1994) and sought the most interpretable approach for combining our measures of exploratory and exploitative innovation (see also Lubatkin et al. 2006). Given the close link between ambidexterity and performance (Gibson and Birkinshaw 2004, He and Wong 2004), we ran four regression analyses with a seven-item measure for performance as the dependent variable (see, e.g., Li and Atuahene-Gima 2001) ( $\alpha=0.81)$. The first unconstrained model treats exploratory and exploitative innovation as separate independent variables. Then, we ran three constrained regression equations in which exploration and exploitation were combined into a single index, first by subtracting exploitation from exploration, second by multiplying exploration and exploitation, and third by summing the two. Following Edwards (1994), we calculated $F$-values based on $R^{2}$ differences of the three models and the unconstrained model. The additive model proved to be superior to the other two approaches, the $F$-test showed no significant loss of information compared to the unconstrained model, and its $R^{2}(0.22)$ is slightly higher than for the multiplicative model $(0.20)$. The subtractive model, however, appeared to have the lowest explanatory power, which resulted in a significant loss of explanatory power. Given these results from Edwards's (1994) test, we measured ambidexterity by adding exploratory and exploitative innovation.

Independent and Mediating Variables. Based on a literature review, we developed a six-item scale for structural differentiation $(\alpha=0.78)$ that taps into the extent that organizations segment their organizational system into spatially dispersed units, each of which tends to develop a particular attribute in relation to its relevant environmental requirements (Lawrence and Lorsch 1967, pp. 3-4). The scale for structural differentiation captures various aspects of differences across units, such as different mindsets, time orientations, functions, and 
product/market domains (Lawrence and Lorsch 1967, Golden and Ma 2003).

We used two measures for capturing formal and informal senior team integration: senior team contingency rewards and senior team social integration. Senior team contingency rewards $(\alpha=0.76)$ refers to the extent to which senior management team incentives, such as bonuses and profit sharing, were tied to overall firm performance. We adapted a four-item measure for contingency rewards from Collins and Clark (2003). The four-item measure for senior team social integration $(\alpha=0.73)$ was adapted from prior studies (O'Reilly et al. 1989, Smith et al. 1994). It captures the attraction to senior management members, satisfaction, and social interaction among team members. Regarding formal and informal organizational integration mechanisms, our study adapted existing measures for cross-functional interfaces and connectedness. Based on Hage and Aiken (1967) and Gupta and Govindarajan (2000), cross-functional interfaces $(\alpha=0.72)$ were measured through a five-item scale. It captures the extent to which firms use cross-functional boundary-spanning integration mechanisms, such as cross-functional teams, projects, and liaison personnel. Connectedness $(\alpha=$ 0.74 ) was measured with a four-item scale adapted from Jaworski and Kohli (1993). It refers to the extent to which employees were networked to various levels of the hierarchy in their organization.

An integrated confirmatory factor analysis on all items pertaining to structural differentiation, formal and informal integration mechanisms, and exploratory and exploitative innovation (with each item constrained to load only on the factor for which it was the proposed indicator) yielded a model that fitted the data moderately well $\left(\chi^{2} /\right.$ degrees of freedom (d.f.) $=1.65$, incremental fit index (IFI) $=0.90$, comparative fit index $(\mathrm{CFI})=0.90$, root mean squared error of approximation $($ RMSEA $)=0.053)$. Item loadings were as proposed and significant $(p<0.01)$. We also performed three additional confirmatory factor analyses (CFAs) in which we grouped items to get better parameter to degree of freedom ratios. The first CFA model contained structural differentiation, exploratory innovation, and exploitative innovation. The second CFA model grouped senior team integration mechanisms and included senior team contingency rewards and senior team social integration. The third CFA model grouped organizational integration mechanisms and contained cross-functional interfaces and connectedness. The fit indices were as follows: Model $1, \chi^{2} /$ d.f. $=2.18, \mathrm{IFI}=0.93, \mathrm{CFI}=0.93$, RMSEA $=0.072$; Model 2, $\chi^{2} /$ d.f. $=1.74$, IFI $=0.98$, $\mathrm{CFI}=0.98, \mathrm{RMSEA}=0.057$; Model 3, $\chi^{2} /$ d.f. $=2.07$, $\mathrm{IFI}=0.95 \mathrm{CFI}=0.94$, RMSEA $=0.068$. Furthermore, all factor loadings were significant $(p<0.01)$. These additional results confirm the convergent and discriminant validity of our scales.
Control Variables. In our empirical study, we controlled for possible alternative explanations by including relevant control variables. First, because larger organizations may have more resources yet may lack the flexibility to achieve ambidexterity, we included the natural logarithm of the number of full-time employees within organizations to account for firm size. Second, it is known that incumbent firms are naturally more inclined toward exploitative efforts (Gilbert 2005), so we included firm age measured by natural logarithm of the number of years from the firm's founding. Third, senior team size could affect the heterogeneity of senior teams and, accordingly, impact the achievement of ambidexterity. Following prior studies, we measured senior team size through the number of senior executives who are responsible for strategy formulation and implementation (e.g., Siegel and Hambrick 2005). Fourth, context or industry effects may influence the extent to which organizations pursue exploratory and exploitative innovation (He and Wong 2004, Sidhu et al. 2007). Accordingly, we included seven industry dummies based on Standard Industry Classification codes: manufacturing, construction, wholesale, transportation, financial services, professional services, and other. Fifth, environmental attributes such as dynamism tend to affect organizations in pursuing exploratory and exploitative innovation (Floyd and Lane 2000). We therefore included a threeitem scale for environmental dynamism $(\alpha=0.70)$ that tapped into the rate of change and the instability of the external environment (Jansen et al. 2006).

\section{Analysis and Results}

Table 1 presents descriptive statistics and correlations for the study variables. Table 2 presents the results of the regression analyses for ambidexterity. To examine multicollinearity, we calculated variance inflation factors (VIFs) for each of the regression equations. The maximum VIF within the models was 1.43 , which is well below the rule-of-thumb cutoff of 10 (Neter et al. 1990).

The baseline model (Model 1) contains the control variables. Model 2 includes the effect of structural differentiation on ambidexterity. Model 3 adds formal and informal integration mechanisms as mediators of the former relationship. Although we explicitly theorize integration mechanisms as mediating variables, we also ran moderation tests (adjusted $R^{2}=0.22$ ) but found no significant interaction effects. This further strengthens our assertions of an intervening effect of integration mechanisms.

To assess the effects of structural differentiation and integration on ambidexterity, we followed a four-step procedure (Baron and Kenny 1986). First, we examined the relationship between structural differentiation and ambidexterity. As shown in Model 2, the coefficient for structural differentiation is positive and significant $(\beta=0.23, p<0.01)$. Second, the mediating senior 


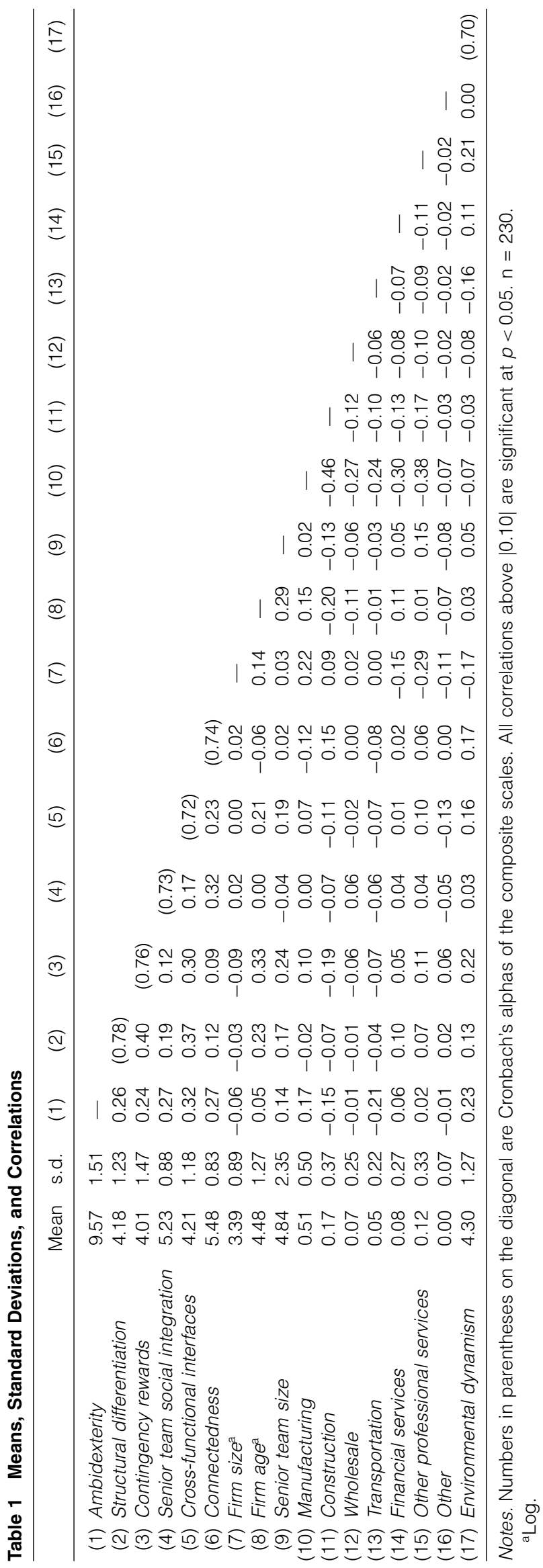

Table 2 Results of Hierarchical Regression Analyses:
Structural Differentiation, Integration, and Structural Differe

\begin{tabular}{lccc}
\hline & \multicolumn{3}{c}{ Ambidexterity } \\
\cline { 2 - 4 } & Model 1 & Model 2 & Model 3 \\
\hline Control variables & & & \\
$\quad$ Firm size & -0.03 & -0.07 & -0.08 \\
Firm age & -0.05 & -0.05 & -0.06 \\
Senior team size & 0.13 & 0.10 & 0.09 \\
Manufacturing & $0.24^{* *}$ & $0.24^{* *}$ & $0.24^{* *}$ \\
Wholesale & 0.08 & 0.08 & 0.07 \\
Transportation & -0.10 & -0.10 & -0.08 \\
Financial services & 0.11 & 0.09 & 0.09 \\
Professional services & 0.05 & 0.05 & 0.02 \\
Other & 0.01 & -0.01 & 0.02 \\
Environmental dynamism & $0.20^{* *}$ & $0.18^{* *}$ & 0.12 \\
Independent variable & & & \\
Structural differentiation & & $0.23^{* *}$ & 0.11 \\
Mediator variables & & & \\
$\quad$ Senior team integration mechanisms & & & \\
$\quad$ Senior team contingency rewards & & & 0.06 \\
$\quad$ Senior team social integration & & & $0.15^{*}$ \\
Organizational integration mechanisms & & & \\
$\quad$ Cross-functional interfaces & & & $0.15^{*}$ \\
$\quad$ Connectedness & & & $0.17^{* *}$ \\
Adjusted $R^{2}$ & 0.09 & 0.14 & 0.23 \\
$\Delta$ adjusted $R^{2}$ & $0.09^{* * *}$ & $0.05^{* *}$ & $0.09^{* * *}$ \\
\hline Note. Standardied & & &
\end{tabular}

Note. Standardized regression coefficients are reported. ${ }^{*} p<0.05,{ }^{* *} p<0.01,{ }^{* * *} p<0.001$.

team integration variables (i.e., senior team contingency rewards and senior team social integration) and organizational integration variables (i.e., cross-functional interfaces and connectedness) need to be significantly related to ambidexterity. As shown in Model 3, however, senior team contingency rewards are not significantly related to ambidexterity $(\beta=0.06$, n.s.). Senior team social integration is positively related to ambidexterity $(\beta=$ $0.15, p<0.05)$. The two indicators for organizational integration mechanisms, cross-functional interfaces $(\beta=$ $0.15, p<0.05)$ and connectedness $(\beta=0.17, p<0.01)$, are both positively related to achieving ambidexterity. Third, the significant relationship between structural differentiation and ambidexterity needs to become insignificant when the mediating variables are introduced in the regression model. As shown in Model 3, the relationship between structural differentiation and ambidexterity becomes insignificant when the four mediating variables are added $(\beta=0.11, p>0.10)$. Fourth, structural differentiation needs to be significantly related to the mediating variables. We ran additional regression analyses with the four mediation variables as dependent variables and structural differentiation as the independent variable with all control variables included. The regression analyses results indicated that structural differentiation was significantly related to the mediating variables contingency rewards $(\beta=0.30, p<0.001)$, social integration 
$(\beta=0.20, p<0.01)$, and cross-functional interfaces $(\beta=0.32, p<0.001)$, but not connectedness $(\beta=$ 0.12 , n.s.).

Overall, the mediating analysis provides various interesting outcomes. First, it does not provide support for Hypothesis 1 about the mediating role of senior team contingency rewards. Although structural differentiation is positively related to senior team contingency rewards, "common fate" incentive systems appear to be not related to achieving ambidexterity. Senior team social integration, however, fully mediates the relationship between structural differentiation and ambidexterity. Our findings support previous assertions concerning the importance of informal senior team integration in ambidextrous organizations. Hypothesis 2 is supported. Second, Hypothesis 3, which proposed a mediating effect of cross-functional interfaces on the relationship between structural differentiation and ambidexterity, is supported. Cross-functional interfaces provide formal integration mechanisms that contribute to establishing linkages between exploratory and exploitative organizational units. Finally, our findings indicate that connectedness does not mediate the relationship between structural differentiation and ambidexterity. Rather, informal social relations within organizations have a direct effect on pursuing exploratory and exploitative innovation simultaneously.

\section{Post Hoc Analysis}

To further verify our research findings, we conducted various additional analyses. First, we used structural equation modeling to assess the fit of the hypothesized model and verify the indirect effect of structural differentiation on ambidexterity. Given our sample size of 230, we used item-averaged composite variables as observed variables (Bagozzi and Yi 1988, Kenny 1979). We fixed the path from each latent construct to its measured variable equal the square root of the reliability coefficient alpha $(\alpha)$ of the measured composite variable, and the amount of error was set to $(1-\alpha)$. The resulting model fitted the data adequately (IFI $=1.00, \mathrm{CFI}=$ 1.00 , standardized root-mean-square residual $(\mathrm{SRMR})=$ 0.025). Moreover, findings replicated the results of the regression analyses. The direct path from structural differentiation toward ambidexterity was nonsignificant $(p>0.10)$. In addition, findings show that senior team social integration $(p<0.01)$ and cross-functional interfaces $(p<0.01)$ mediate the relationship between structural differentiation and ambidexterity. Second, given the results of the Edwards's (1994) test as explained earlier (and the insignificant difference between the additive and multiplicative models), we conducted additional regression analyses with the multiplicative interaction of exploratory and exploitative innovation as an alternative measurement of ambidexterity (Gibson and Birkinshaw
2004, He and Wong 2004). We repeated the tests of the hypotheses using this alternative measurement as the dependent variable and found similar results. The findings regarding the mediating role of senior team and organizational integration mechanisms replicated the earlier findings with the additive model as the measurement of ambidexterity. Hypothesis 1 (senior team contingency rewards) was not supported, Hypothesis 2 was supported (senior team social integration), Hypothesis 3 was supported (cross-functional interfaces), and Hypothesis 4 was not supported (connectedness). Overall, our Post hoc analysis provides strong support for our research findings.

\section{Discussion and Conclusion}

An important stream of studies investigates specific organizational attributes that influence a firm's ambidexterity, or effectiveness, in pursuing seemingly contradictory activities simultaneously, which is difficult to achieve in practice (Raisch and Birkinshaw 2008). Conceptual arguments assert that achieving ambidexterity imposes considerable challenges on organizations, because of the necessity to allow integration and application of spatially dispersed exploratory and exploitative efforts (Smith and Tushman 2005). Yet, our understanding of antecedents of ambidexterity remains rather unclear.

Our study underscores previous assertions that structural differentiation provides an important yet insufficient structural attribute for achieving ambidexterity. Structural differentiation helps organizations to buffer experimentation and the development of new competences and capabilities from ongoing operations (e.g., Gilbert 2006, Tushman and O'Reilly 1996). It generates structural flexibility to adapt to local environmental demands (Volberda 1996), yet exploratory and exploitative activities need to be mobilized, integrated, and applied across inconsistent organizational units. Accordingly, our study affirms the importance of structural differentiation within ambidextrous organizations; however, it suggests that ambidextrous organizations need to resolve conflicting tensions in senior teams, and to integrate diverse knowledge sources across differentiated exploratory and exploitative units (Kogut and Zander 1992, Smith and Tushman 2005). We argue, therefore, that ambidextrous organizations require a dynamic capability that enables them to mobilize, coordinate, and integrate dispersed contradictory efforts, and to allocate, reallocate, combine, and recombine resources and assets across dispersed exploratory and exploitative units (O'Reilly and Tushman 2007, Teece 2007). Our findings move research on the relationship between structural differentiation and ambidexterity beyond main effects (e.g., Gilbert 2006). We suggest that future research needs 
to examine distinct integration mechanisms as important contenders for the dynamic capability to pursue exploratory and exploitative innovation simultaneously. Our study leads us to suggest that the previously asserted effect of structural differentiation on ambidexterity is indirect, operating through both informal senior team integration (i.e., senior team social integration) and formal organizational integration (i.e., cross-functional interfaces) mechanisms. In this sense, our study contributes to previous literatures that theorized for the subsequent integration of differentiated exploratory and exploitative activities (Siggelkow and Levinthal 2003, Westerman et al. 2006). Ambidextrous organizations should enact differentiated exploratory and exploitative activities by managing resource and routine reconfiguration (Zahra et al. 2006). Our study argues that organizations are able to create value for both new and existing customers only when they are able to structure their technology portfolios and subsequently integrate differentiated activities to capitalize on them. In finding support for this notion, our study provides new insights about which specific integration mechanisms within organizations are required to coordinate, implement, and apply exploratory and exploitative activities in dispersed organizational units and to achieve ambidexterity.

Interestingly though, our study fails to support the hypothesis that senior team contingency rewards contribute to the achievement of ambidexterity. Although prior studies have suggested that "common fate" incentive systems reduce interpersonal competition and foster a firmwide view and collaboration (Edmondson et al. 2003, Wageman 1995), our study shows that they do not contribute to alleviating potential problems associated with spatially separating exploratory and exploitative efforts. A possible explanation for the positive but insignificant relationship could be that the creation of outcome interdependency through senior team contingency rewards does not encourage senior team members to reconcile conflicting interests across differentiated exploratory and exploitative units. In this vein, Wageman (1995) showed that task (i.e., stemming from the process by which the work is carried out) rather than outcome interdependency resulted in greater cooperation, high-quality group processes, and member satisfaction. Although group reward systems are known to stimulate cooperative effort and motivation, this effort may not necessarily result in balanced decision making and managing strategic contradictions in senior teams (Wageman and Baker 1997, Smith and Tushman 2005). Our study hints that overcoming multiple conflicting strategic agendas and reinforcing integrative thinking in ambidextrous organizations requires senior team integrative mechanisms that go beyond establishing outcome interdependency. Although senior team contingency rewards may be beneficial to achieving ambidexterity under certain organizational and industrial conditions (e.g., Jansen et al. 2008, O'Reilly and Tushman 2004), future studies should examine how interdependency affects the impact of senior team contingency rewards on the achievement of ambidexterity across spatially dispersed exploratory and exploitative units.

Although our study indicates that common fate incentive systems do not provide necessary integrative value across differentiated exploratory and exploitative units, it shows that senior team social integration mediates the relationship between structural differentiation and ambidexterity (e.g., O'Reilly and Tushman 2004). Social integration engenders social mechanisms such as trust and reciprocity in senior teams (Lubatkin et al. 2006). It encourages team members to openly discuss and debate conflicting demands, goals, and aspirations of their associated exploratory and exploitative units. Such critical debate helps to overcome strategic contradictions and resolve conflicting situations arising from integrating and implementing spatially dispersed exploratory and exploitative activities. Our study increases our understanding of the importance of senior team social integration in structurally ambidextrous organizations (Gibson and Birkinshaw 2004).

Regarding the mediating role of organizational integration mechanisms, our study contributes to prior literatures concerning the importance of formal linkages across differentiated exploratory and exploitative organizational units in ambidextrous organizations (Gilbert 2006). By providing formal integration devices, our findings indicate that cross-functional interfaces are effective integrative mechanisms in differentiated ambidextrous organizations. Boundary-spanning mechanisms contribute to the development of a common language and ensure the capture, interpretation, and integration of knowledge sources across differentiated exploratory and exploitative units (Carlile 2004, De Luca and Atuahene-Gima 2007). An important feature of cross-functional interfaces is their ability to deepen flows of knowledge between exploratory and exploitative units without interrupting their internal processes (Gilbert 2006). Our study's finding on the mediating effect of cross-functional interfaces adds to the emergent dialogue on the hierarchical level at which integration of exploratory and exploitative efforts need to happen. It indicates that the idea that differentiated exploratory and exploitative efforts are integrated at the senior team level has to be expanded by incorporating lower-level cross-functional linkage devices as well (Gilbert 2006, Westerman et al. 2006). Our study contributes to these recent conceptual assertions that, in addition to senior team social integration, formal organizational integration mechanisms are needed to 
provide necessary horizontal linkages across differentiated exploratory and exploitative units in ambidextrous organizations.

Regarding informal social relations, our study reveals that connectedness does not mediate the relationship between structural differentiation and ambidexterity, but rather contributes to achieving ambidexterity directly. A possible explanation could be that it becomes more difficult to develop and maintain informal social relations between organizational members across differentiated exploratory and exploitative units. Given our finding that senior team social integration fully mediates the relationship between structural differentiation and ambidexterity, it may be the case that structural differentiation is only detrimental to informal social relations at lower hierarchical levels. Future research should shed more light on this potential differential impact of structural differentiation on senior team social integration and connectedness. Notwithstanding this potential effect, our study shows that ambidextrous organizations need to implement more formal organizational integration devices, such as liaison personnel and teams, rather than informal social relations to integrate and apply differentiated exploratory and exploitative efforts at lower hierarchical levels. As organizational members with a larger pool of informal relations may be able to exploit or explore to their advantage (Lin et al. 2007), our study may also suggest that connectedness contributes to establishing a conducive context for achieving ambidexterity directly rather than indirectly by generating resource and knowledge flows across differentiated units. Specific features of dense social relations, such as discipline, trust, and support, have been shown to directly affect the achievement of contextual ambidexterity. They encourage organizational members to make their own judgments as to how to best divide their time between conflicting demands (Gibson and Birkinshaw 2004). Further exploratory research is necessary to explore this possibility and understand how connectedness enables the achievement of contextual ambidexterity within organizations.

Our study reveals that ambidextrous organizations should carefully design and implement specific types of integration mechanisms at different hierarchical levels. At the corporate level, ambidextrous organizations should encourage (informal) social integration among senior team members. At lower hierarchical levels, however, ambidextrous organizations should establish more formal cross-functional interfaces that deepen knowledge flows across differentiated units yet retain the contradictory processes and time orientation within exploratory and exploitative units. This distinction echoes prior research stating that as one comes closer to senior management, integration efforts become more broad, less clear cut, and more complex in nature (Egelhoff 1991, Floyd and Lane 2000). At the senior team level, managers face both high differentiation as well as high interdependency, requiring frequent adjustments and more informal means of integration (Daft and Lengel 1986, Hambrick et al. 2008). At lower levels in ambidextrous organizations, organizational members still face high differentiation but lower interdependency, calling for more formal integration mechanisms (Daft and Lengel 1986). Through this richer explanation and empirical assessment of these multilevel dynamics in ambidextrous organizations, we contribute to a greater clarity and better understanding of how organizations may effectively pursue exploratory and exploitative innovation simultaneously to achieve ambidexterity.

\section{Limitations and Future Research Suggestions}

Our study presents a first step toward uncovering the interrelationship between differentiation, integration, and achieving ambidexterity, and study limitations suggest the need for additional research. First, future studies may include additional senior team and organizational attributes. For instance, previous research has argued that leadership behaviors such as transformational and transactional leadership contribute to exploration and exploitation within an organization (Jansen et al. 2009), and may also may foster an organizational context suitable for hosting contradictory forces (Vera and Crossan 2004). Additionally, future research may capture multiple levels of analysis and uncover how unit-level and firm-level or firm-level and interfirm-level characteristics contribute to achieving ambidexterity (see, e.g., Simsek 2009). Second, our study focused on spatially separating exploratory and exploitative activities in different organizational units as an important way of achieving ambidexterity. Organizations may, however, utilize other structures or systems to reconcile conflicting tensions, such as temporal separation, a system in which organizations focus on exploratory innovation at one point in time followed by a focus on exploitation at subsequent points in time (Gupta et al. 2006). Future research may uncover differential effects of structural attributes for spatial and temporal separation of exploratory and exploitative innovation. Third, although we took great care in separating collection of data on the independent and dependent variables as well as the use of multiple respondents that provide valuable methodological contributions, future longitudinal research is necessary to investigate how structural differentiation and integration are developed and impacted over time.

\section{Acknowledgments}

The authors would like to thank Special Issue Editor Gilbert Probst and two anonymous referees for their valuable comments. 


\section{Appendix. Measures and Items}

Exploratory innovation (Jansen et al. 2006)

Our organization accepts demands that go beyond existing products and services

We commercialize products and services that are completely new to our organization

We frequently utilize new opportunities in new markets

Our organization regularly uses new distribution channels

Exploitative innovation (Jansen et al. 2006)

We frequently make small adjustments to our existing products and services

We improve our provision's efficiency of products and services

We increase economies of scales in existing markets

Our organization expands services for existing clients

Structural differentiation

Innovation and production activities are structurally separated within our organization

Our business units are specialized in specific functions and/or markets

We serve our customers needs from separate departments

The line and staff departments are clearly separated within our organization

Our organization has separate units to enhance innovation and flexibility

We have units that are either focused on the short term or the long term

Senior team contingency rewards (Collins and Clark 2003)

Senior team members' variable pay consists of multiple performance-based elements

Senior team members' variable pay is based on average firm performance

Incentive-based pay for the senior team is based on how well the organization is performing as a whole

Incentive-based pay for the senior team is based on the performance of its members organizational unit ${ }^{\circledR}$

Senior team social integration (O'Reilly et al. 1989, Smith et al. 1994)

The members of the senior team are quick to defend each other from criticism by outsiders

Members of the senior team get along with each other very well

Members of the senior team are always prepared to work together and support each other

There is a lot of competition within the senior team ${ }^{\circledR}$

Cross-functional interfaces (Hage and Aiken 1967, Gupta and Govindarajan 2000)

Employees are regularly rotated between jobs in our organization

There is regular talk about possibilities for collaboration between units

Our organization coordinates information sharing between units through a knowledge network

We have cross-functional teams to exchange knowledge between departments

Our organization uses temporary workgroups for collaboration between units on a regular basis

Connectedness (Jaworski and Kohli 1993)

In our organization, there is ample opportunity for informal "hall talk" among employees

In this firm, employees from different departments feel comfortable calling each other when the need arises

People around here are quite accessible to each other

In this organization, it is easy to talk with virtually anyone you need to, regardless of rank or position

Note. All items were measured on a seven-point scale, anchored by $1=$ strongly disagree and $7=$ strongly agree; ${ }^{\circledR}$ reversed item.

\section{References}

Abernathy, W. J., K. B. Clark. 1985. Innovation: Mapping the winds of creative destruction. Res. Policy 14 3-22.

Bagozzi, R. P., Y. Yi. 1988. On the evaluation of structural equation models. J. Acad. Marketing Sci. 16(1) 74-95.

Barkema, H. G., O. Shvyrkov. 2007. Does top management team diversity promote or hamper foreign expansion? Strategic Management J. 28(7) 663-680.

Barney, J. 1991. Firm resources and sustainable competitive advantage. J. Management 170(1) 99-120.

Baron, R. M., D. A. Kenny. 1986. The moderator-mediator variable distinction in social psychological research: Conceptual, strategic, and statistical considerations. J. Personality Soc. Psych. 51 1173-1182.

Benner, M. J., M. L. Tushman. 2003. Exploitation, exploration, and process management: The productivity dilemma revisited. Acad. Management Rev. 28 238-256.

Bloom, M. 1999. The performance effects of pay dispersion on individuals and organizations. Acad. Management J. 42 25-40.
Bower, J. L. 1970. Managing the Resource Allocation Process. Harvard Business School Press, Boston.

Burgelman, R. A. 2002. Strategy as vector and the inertia of coevolutionary lock-in. Admin. Sci. Quart. 47(2) 325-358.

Carlile, P. R. 2004. Transferring, translating, and transforming: And integrative framework for managing knowledge across boundaries. Organ. Sci. 15 555-568.

Child, J. 1984. Organization-A Guide to Problems and Practice. Harper and Row, New York.

Cohen, W. M., D. A. Levinthal. 1990. Absorptive capacity: A new perspective on learning and innovation. Admin. Sci. Quart. 35(1) $128-152$.

Collins, C. J., K. D. Clark. 2003. Strategic human resource practices, top management team social networks, and firm performance: The role of human resources practices in creating organizational competitive advantage. Acad. Management J. 46 740-751.

Daft, R. L., R. H. Lengel. 1986. Organizational information requirements, media richness and structural design. Management Sci. 32 554-571. 
Danneels, E. 2002. The dynamics of product innovation and firm competencies. Strategic Management J. 23 1095-2022.

De Cremer, D., D. van Knippenberg, E. van Dijk, E. van Leeuwen. 2008. Cooperating if one's goals are collective-based: Social identification effects in social dilemmas as a function of goal transformation. J. Appl. Soc. Psych. 38(6) 1562-1579.

De Luca, L. M., K. Atuahene-Gima. 2007. Market knowledge dimensions and cross-functional collaboration: Examining the different routes to product innovation performance. J. Marketing $\mathbf{7 1}$ 95-112.

Dougherty, D. 2001. Reimaging the differentiation and integration of work for sustained product innovation. Organ. Sci. 12 612-632.

Duncan, R. B. 1976. The ambidextrous organization: Designing dual structures for innovation. R. H. Kilmann, L. R. Pondy, D. Slevin, eds. The Management of Organization. North Holland, New York, 167-188.

Edmondson, A. C., M. A. Roberto, M. D. Watkins. 2003. A dynamic model of top management team effectiveness: Managing unstructured task streams. Leadership Quart. 14 297-325.

Edwards, J. R. 1994. The study of congruence in organizational behavior research: Critique and a proposed alternative. Organ. Behav. Human Decision Processes 58 51-100.

Egelhoff, W. G. 1991. Information-prosessing theory and the multinational enterprise. J. Internat. Bus. Stud. 22(3) 341-368.

Eisenhardt, K. M., J. A. Martin. 2000. Dynamic capabilities: What are they? Strategic Management J. 21 1105-1121.

Eisenhardt, K. M., J. L. Kahwajy, L. J. Bourgeois, III. 1997. Conflict and strategic choice: How top management teams disagree. California Management Rev. 75 77-85.

Floyd, S. W., P. J. Lane. 2000. Strategizing throughout the organization: Managing role conflict in strategic renewal. Acad. Management Rev. 25 154-177.

Galbraith, J. R. 1973. Designing Complex Organizations. Addison Wesley, Reading, MA.

Galunic, D. C., K. M. Eisenhardt. 2001. Architectural innovation and modular corporate forms. Acad. Management J. 44 1229-1249.

Garud, R., P. R. Nayyar. 1994. Transformative capacity: Continual structuring by intertemporal technology transfers. Strategic Management J. 15 365-386.

Ghoshal, S., H. Korine, G. Szulanski. 1994. Interunit communication in multinational corporations. Management Sci. 40 96-110.

Gibson, C. B., J. Birkinshaw. 2004. The antecedents, consequences, and mediating role of organizational ambidexterity. Acad. Management J. 47 209-226.

Gilbert, C. G. 2005. Unbundling the structure of inertia: Resource versus routine rigidity. Acad. Management J. 48 741-763.

Gilbert, C. G. 2006. Change in the presence of residual fit: Can competing frames coexist? Organ. Sci. 17 150-167.

Golden, B. R., H. Ma. 2003. Mutual forbearance: The role of intrafirm integration and rewards. Acad. Management Rev. 28 479-493.

Gupta, R., V. Govindarajan. 2000. Knowledge flows within multinational corporations. Strategic Management J. 21 473-496.

Gupta, A. K., K. G. Smith, C. E. Shalley. 2006. The interplay between exploration and exploitation. Acad. Management J. 49 693-706.

Hage, J., M. Aiken. 1967. Program change and organizational properties: Comparative analysis. Amer. J. Sociol. 72 503-519.

Hall, R. H. 1977. Organizations: Structure and Process. Prentice-Hall, Englewood Cliffs, NJ.

Hambrick, D. C., A. von Werder, E. J. Zajac. 2008. New directions in corporate governance research. Organ. Sci. 19 381-385.
Hansen, M. T. 2002. Knowledge networks: Explaining effective knowledge sharing in multiunit companies. Organ. Sci. 13 232-248.

Harris, J., P. Bromiley. 2007. Incentives to cheat: The influence of executive compensation and firm performance on financial misrepresentation. Organ. Sci. 18 350-367.

Harrison, D. A., K. H. Price, J. H. Gavind, A. T. Florey. 2002. Time, teams, and task performance: Changing effects of surface- and deep-level diversity on group functioning. Acad. Management $J$. 45 1029-1045.

He, Z., P. Wong. 2004. Exploration vs. exploitation: An empirical test of the ambidexterity hypothesis. Organ. Sci. 15 481-494.

Helfat, C., M. A. Peteraf. 2003. The dynamic resource-based view: capability lifecycles. Strategic Management J. 24 997-1010.

Henderson, R., I. Cockburn. 1994. Measuring competence? Exploring firm effects in pharmaceutical research. Strategic Management J. 15 63-84.

Hill, C. W. L., F. T. Rothaermel. 2003. The performance of incumbent firms in the face of radical technological innovation. Acad. Management Rev. 28 257-274.

Iansiti, M., K. B. Clark. 1994. Integration and dynamic capability: Evidence from product development in automobiles and mainframe computers. Indust. Corporate Change 3 557-605.

James, L. R., R. G. Demaree, G. Wolf. 1984. Estimating within-group interrater reliability with and without response bias. J. Appl. Psych. 69 85-98.

Jansen, J. J. P., F. A. J. van den Bosch, H. W. Volberda. 2005. Managing potential and realized absorptive capacity: How do organizational antecedents matter? Acad. Management J. 48 999-1015.

Jansen, J. J. P., F. A. J. van den Bosch, H. W. Volberda. 2006. Exploratory innovation, exploitative innovation, and performance: Effects of organizational antecedents and environmental moderators. Management Sci. 52 1661-1674.

Jansen, J. J. P., G. George, F. A. J. van den Bosch, H. W. Volberda. 2008. Senior team attributes and organizational ambidexterity: The moderating role of transformational leadership. J. Management Stud. 45 982-1007.

Jansen, J. J. P., D. Vera, M. Crossan. 2009. Strategic leadership for exploration and exploitation: The moderating role of environmental dynamism. Leadership Quart. 20(1) 5-18.

Jaworski, B. J., A. K. Kohli. 1993. Market orientation: Antecedents and consequences. J. Marketing 57 53-70.

Jehn, K. A., C. Chadwick, S. Thatcher. 1997. To agree or not to agree: Diversity, conflict, and group outcomes. Internat. J. Conflict Management 8 287-306.

Kenny, D. A. 1979. Correlation and Causality. Wiley, New York.

Kogut, B., U. Zander. 1992. Knowledge of the firm, combinative capabilities, and the replication of technology. Organ. Sci. 3 383-397.

Krackhardt, D., R. Stern. 1988. Informal networks and organizational crises: An experimental simulation. Soc. Psych. Quart. 51 123-140.

Lawrence, P. R., J. W. Lorsch. 1967. Differentiation and integration in complex organizations. Admin. Sci. Quart. 12 1-47.

Levinthal, D. A., J. G. March. 1993. The myopia of learning. Strategic Management J. 14 95-112.

Li, H., K. Atuahene-Gima. 2001. Product innovation strategy and the performance of new technology ventures in china. Acad. Management J. 44 1123-1134.

Lin, Z., H. Yang, I. Demirkan. 2007. The performance consequences of ambidexterity in strategic alliance formations: Empirical investigation and computational theorizing. Management Sci. 53 $1645-1658$ 
Lubatkin, M. H., Z. Simsek, Y. Ling, J. F. Veiga. 2006. Ambidexterity and performance in small- to medium-sized firms: The pivotal role of TMT behavioral integration. J. Management 32(5) 1-27.

March, J. 1991. Exploration and exploitation in organizational learning. Organ. Sci. 2 71-87.

March, J., H. Simon. 1958. Organizations. John Wiley \& Sons, New York.

Martinez, J. I., J. C. Jarillo. 1989. The evolution of research on coordination mechanisms in multinational corporations. J. Internat. Bus. Stud. 20(3) 489-514.

Martinez, J. I., J. C. Jarillo. 1991. Coordination demands of international strategies. J. Internat. Bus. Stud. 22(3) 429-444.

Michel, J. G., D.C. Hambrick. 1992. Diversification posture and top management team characteristics. Acad. Management J. $\mathbf{3 5}$ 9-37.

Nahapiet, J., S. Ghoshal. 1998. Social capital, intellectual capital, and the organizational advantage. Acad. Management Rev. 23 $242-266$.

Nelson, R. E. 1989. The strength of strong ties: Social networks and intergroup conflict in organizations. Acad. Management J. 32 $377-401$.

Neter, J., W. Wasserman, M. H. Kutner. 1990. Applied Linear Statistical Models. Homewood, Irwin, IL.

O'Reilly, C. A., M. L. Tushman. 2004. The ambidextrous organization. Harvard Bus. Rev. 82 74-82.

O'Reilly, C. A., M. L. Tushman. 2007. Ambidexterity as a dynamic capability: Resolving the innovator's dilemma. Res. Organ. Behav. 28 1-60.

O'Reilly, C. A., D. F. Caldwell, W. P. Barnett. 1989. Work group demography, social integration, and turnover. Admin. Sci. Quart. 34(1) $21-38$.

Orton, J. D., K. E. Weick. 1990. Loosely coupled systems: A reconceptualization. Acad. Management Rev. 15 203-223.

Pfeffer, J. 1995. Competitive Advantage Through People: Unleashing the Power of Work Force. Harvard Business School Press, Boston.

Postrel, S. 2002. Islands of shared knowledge: Specialization and mutual understanding in problem-solving teams. Organ. Sci. $\mathbf{1 3}$ 303-320.

Prabhu, J. C., R. K. Chandy, M. E. Ellis. 2005. The impact of acquisitions on innovation: Poison pill, placebo, or tonic? J. Marketing 69(1) 114-130.

Raisch, S., J. Birkinshaw. 2008. Organizational ambidexterity: antecedents, outcomes, and moderators. J. Management 34 375-409.

Rindfleisch, A., C. Moorman. 2001. The acquisition and utilization of information in new product alliances: A strength-of-ties perspective. J. Marketing 65(2) 1-18.

Shaw, J. D., N. Gupta, J. E. Delery. 2002. Pay dispersion and workforce performance: Moderating effects of incentives and interdependence. Strategic Management J. 23 491-512.

Sheremata, W. A. 2000. Centrifugal and centripetal forces in radical new product development under time pressure. Acad. Management Rev. 25 389-408.

Sidhu, J. S., H. R. Commandeur, H. W. Volberda. 2007. The multifaceted nature of exploration and exploitations' value of supply, demand, and spatial search for innovation. Organ. Sci. 18 20-38.
Siegel, P. A., D. C. Hambrick. 2005. Pay disparities within top management groups: Evidence of harmful effects on performance of high-technology firms. Organ. Sci. 16 259-274.

Siggelkow, N., D. A. Levinthal. 2003. Temporarily divide to conquer: Centralized, decentralized, and reintegrated organizational approaches to exploration and adaptation. Organ. Sci. 14 650-669.

Simsek, Z. 2009. Organizational ambidexterity: Towards a multilevel understanding. J. Management Stud. 46(4) 597-624.

Sirmon, D. G., M. A. Hitt, R. D. Ireland. 2007. Managing firm resources in dynamic environments to create value: Looking inside the black box. Acad. Management Rev. 32 273-292.

Slavin, R. E. 1996. Cooperative Learning: Theory, Research, and Practise. Allyn and Bacon, London.

Smith, K. G., K. A. Smith, H. P. Sims, D. P. O’Bannon, J. A. Scully. 1994. Top management team demography and process: The role of social integration and communication. Admin. Sci. Quart. 39(3) 412-438.

Smith, W. K., M. L. Tushman. 2005. Managing strategic contradictions: A top management model for managing innovation streams. Organ. Sci. 16 522-536.

Teece, D. J. 2007. Explicating dynamic capabilities: The nature and microfoundations of (sustainable) enterprise performance. Strategic Management J. 28 1319-1350.

Teece, D. J., G. Pisano, A. Shuen. 1997. Dynamic capabilities and strategic management. Strategic Management J. 18 509-533.

Tsai, W. 2002. Social structure of "coopetition" within a multiunit organization: Coordination, competition, and intraorganizational knowledge sharing. Organ. Sci. 13 179-190.

Tsai, W., S. Ghoshal. 1998. Social capital and value creation: The role of intrafirm networks. Acad. Management J. 41 464-476.

Tushman, M. L., C. A. O'Reilly. 1996. Ambidextrous organizations: Managing evolutionary and revolutionary change. California Management Rev. 38(4) 8-30.

Tushman, M. L., W. Smith, R. C. Wood, G. Westerman, C. A. O'Reilly. 2006. Organizational designs and innovation streams. Working paper, Harvard Business School, Boston.

Van De Ven, A. H., A. L. Delbecq, R. Koenig. 1976. Determinants of coordination modes within organizations. Amer. Sociol. Rev. 41(2) 322-338.

Venkatraman, N., C.-H. Lee, B. Iyer. 2006. Strategic ambidexterity and sales growth: A longitudinal test in the software sector. Presentation, Academy of Management Annual Meeting, Honolulu.

Vera, D., M. Crossan. 2004. Strategic leadership and organizational learning. Acad. Management Rev. 29 222-240.

Volberda, H. W. 1996. Toward the flexible form: How to remain vital in hypercompetitive environments. Organ. Sci. 7 359-374.

Wageman, R. 1995. Interdependence and group effectiveness. Admin. Sci. Quart. 40 145-180.

Wageman, R., G. Baker. 1997. Incentives and cooperation: The joint effects of task and reward interdependence on group performance. J. Organ. Behavior 18 139-158.

Westerman, G., W. F. McFarlan, M. Iansiti. 2006. Organizational design and effectiveness over the innovation life cycle. Organ. Sci. 17 230-238.

Winter, S. G. 2003. Understanding dynamic capabilities. Strategic Management J. 24 991-995.

Zahra, S. A. 1996. Governance, ownership, and corporate entrepreneurship: The moderating impact of industry technological opportunities. Acad. Management J. 39 1713-1735.

Zahra, S. A., H. J. Sapienza, P. Davidsson. 2006. Entrepreneurship and dynamic capabilities: A review, model, and research agenda. J. Management Stud. 43 917-955. 